\title{
The Evolution Of One Practitioner's Coach Approach: Taking The Coaching Turn
}

\author{
Daniel Doherty \\ Middlesex, UK
}

\begin{abstract}
This largely autoethnographic paper explores the early trajectory of one consultant's career through the seventies and eighties, seeking to detect the point at which this practice took the 'coaching turn'. The purpose of conducting this piece of personal exploration is to discover what the core of a 'coach approach' might have comprised before coaching become professionalized and codified; and perhaps to ask what of the original inspiration behind the coaching impulse might have been lost in the process of professionalization. Comparisons are then drawn between this historical evolution of coaching practice and the choices facing coaches currently setting out to establish their practice in a contemporary setting; and to ask what they might take from this history.
\end{abstract}

Keywords: coaching profession, coach approach, organizational development, autoethnography

\section{Introduction}

I write this piece as a practicing coach with a track record of over 30 years of executive coaching practice, as well as a late-convert academic who for the past 10 years has been adopting a critical perspective on coaching practice, and on the development of coaching theory drawn from coaching practice.

I was intrigued by this call for papers, titled 'A Coach Approach,' which immediately triggered various streams of thought that might be pursued. One provocation was to ask questions as to the possible singularity of coaching identity and of coaching practice. It suggested that I might write a piece that would generalize upon the broad trajectory of coaching over the past forty years, from my perspective on the evolution of the coaching profession across various geographies. It also begged the question as to how I have approached coaching, and how it has approached me, over the past thirty years. The invitation reminded me of times when I approached coaching; and when I have avoided it. In the end what I have decided to share here in this paper is

This is an Open Access article distributed under the terms of the Creative Commons Attribution (CC BY) License which permits use, distribution and reproduction in any medium, provided the original work is properly cited. 
a personal perspective on the trajectory that my coaching practice has followed during its early, formative years, in an attempt to reveal what shaped that practice, in a generation before 'coaching' with a capital 'C' was legitimated as a professionalized field and practice (to my mind this legitimation occurred when coaching hit the mainstream of management practice and thought in the early nineties.)

My interest in exploring this personal narrative is to detect the point at which my practice took the 'coaching turn' - when that bundle of behaviors, beliefs, practices, and values that tacitly represented a coaching approach in my work, were projected by me (and others) out into the world as my coaching offering. The purpose of conducting this piece of personal exploration is to seek what the core of a coach approach might have comprised before coaching became professionalized and codified, and perhaps to ask what might have been lost in the process of professionalization. I draw upon a survey of fellow travelers from the coaching world whose trajectories evolved within the same timeframe as my own, and followed somewhat similar pathways, underpinned by shared values. I then go on to compare and contrast the evolution of my practice with the choices facing a coach who would be setting out right now to establish their practice in a contemporary setting, and to ask what it is they might take from my history.

It is never easy to trace the past, and of course memory is selective. I write in full awareness that this account is highly subjective, and that in constructing this narrative, some events and episodes are highlighted, while others remain in the shadow. I also confine this narrative to conscious memory, rather than at this stage seeking to evacuate the early stages of my personality development, while fully acknowledging that those stages contain clues as to my current coaching approach. This decision to exclude my early development is made in part in cognizance of space limitations, and also borne of a hypothesis that many of the factors that have shaped my practice will show up in the dilemmas and opportunities that I face and the choices I make in the face of those forces.

\section{The evolution of my coaching practice}

I would say that the genesis of my coaching approach occurred in the early seventies, largely through the agency of experiential learning. I developed an earlier taste for learner-centered methods between ages 11 to 14, when I attended a highly experimental co-ed school in the English 
Midlands, where the emphasis was upon discovery learning, allowing the learner's inner wisdom to guide the discovery learning process. However, this enlightenment was to prove short lived. My father's next job move was to mean that this false dawn was brutally replaced by my subsequent experience at a single-sex faith school, where the founding pedagogical principle was to physically beat and psychologically bully learning into you through a process loosely described as teaching. However, despite this disconsolate experience, the early imprint of discovery learning remained deep within me, awaiting resuscitation.

My passion and affinity for experiential learning was fully kindled while studying for a postgraduate MBA-type Diploma at Bath University UK, in 1972 where I discovered that learning could, once more, be entirely engaging and enjoyable, as well as testing. My eyes were open to the possibility that the learner could be in charge of his or her learning process. Through exposure to the work of Kolb (1984), and through participation in a variety of experiential exercises judiciously plundered from the Pfeiffer and Jones group facilitators handbook (1977) - mediated with some sensitive facilitation - I experienced my damascene moment. At that moment I felt I knew, at some core level in my being, that in experiential learning lay an approach that made absolute intuitive sense to me, providing deep personal insight for self, for others, for whole organizations. Over and above this personal growth dimension, it was also clear that Organisation Development (OD) practice, a field that was emergent at that time, would need at its heart just such an experientially based approach if it were to flourish and grow beyond abstract intellectualization. It also opened up the possibility that here was a way of engaging with the world, and perceiving meaning within it that could profitably engage me for the rest of my life. In a world that at that time was full of industrial conflict, 'soft' process' of OD offered an alternative way through, and my strongest wish was to run with that.

A difficulty with this OD / experiential learning 'vocation' at that time, in 1973, was that it was not equivalent to 'becoming' an accountant, or joining the Roman Catholic Church or the Air Force. There were no recognized career pathways, and precious little evidence of organizations, corporate or otherwise, advocating and fully practicing such an alternative approach to learning. At Bath University, I encountered an independent OD consultant who shared his work and approach with us. I was delighted to be confirmed in the view that independent consulting could indeed be a viable longer-term career goal. However, I knew of no direct way of gaining entry to an independent consulting practice, given that I had minimal experience of 
the world, so I clearly needed to gain relevant experiences to provide an authentic career backdrop to enable me to manifest my consulting aspirations. At this time no mention was made of 'coaching' as an explicit practice, though clearly it underpinned much of this burgeoning OD approach.

In the end, I was fortunate to be offered a job at British Steel Corporation (BSC) Head Office Education Department that afforded the possibility of engagement with experiential learning methods through their programme for Training of Training Officers, where I learned under the tutelage of Tom Boydell $(1991,1996)$ and Mike Pedler $(1990,1991)$ of Sheffield Polytechnic (now named Sheffield Hallam University). The reputation of these two educationalists preceded them, as their alternative 'learner-centered approach' to management education had already made quite an impact on my conservatively inclined Education and Training colleagues at British Steel Head Office. In an issue of the otherwise staid journal 'Industrial Training International' in 1973, Boydell and Pedler had written an article on 'learner-centered approaches.' This article proved so provocative that my boss felt inclined to write a letter to the editor, complaining of the article's ill-considered juvenile ideas and tone. He was quite concerned at the company I was keeping.

One early memory of these two learning practitioners occurred when I was escorting a group of visiting Mexican engineers on an exchange visit to Sheffield, then a premier steel town. As an ice-breaking activity for this group, Boydell and Pedler asked us to illustrate on individual sheets of flip chart paper a drawing depicting our journey through life to date, together with some indications of our primary cultural influences. This was followed by a subsequent exercise where we each were given a piece of fruit, and asked to draw upon the inspiration derived from contemplation of the fruit's fleshy exterior to reflect on human diversity, and on our own singular uniqueness within that diversity. The Mexicans were highly receptive to this approach, which surprised and intrigued me. I began to understand why BSC were trusting this otherwise off-the-wall pair with the responsibility of the assimilation of, and ensuing learning design for this important group of visitors. And I was drawn towards an approach that would embrace whole life and uniqueness, rather than processing learning in mechanistic fashion. I realized at that point that such an approach (it could even have been termed a coaching approach) could work in the 'real world.' 
In part inspired by a wish to be in proximity with these two and their unconventional work, I took a transfer to a Sheffield steel works with a long heritage in learning innovation. The head of education and training at the steel plant said he wanted me to work there as he was attracted towards my inclination to 'seek the truth'. He felt that this quality would help to refresh and renew established practice. And I was flattered that he noticed, and was determined to live up to his expectation.

During my time at these steel works I had the opportunity to experiment with experiential learning methods, through some leading innovations in supervisory training, and also through the development and assimilation of graduate entrants. There was continuing satisfaction and development to be had through involvement with the TOTO work in developing trainers and learning facilitators, and I made a breakthrough of a kind when designing and facilitating a week long OD session, in truth more like an encounter group, between works managers and worker directors.

Mike Pedler had been a lecturer at the Workers Educational Association (WEA) in Manchester UK, and had direct experience of the inwardness and suffocation of the Sheffield steel environment. This experience meant that Mike was uniquely positioned to offer me the encouragement to persevere, and experiment in the face of the dead hand of engineering tradition. I well remember how uplifting it was to work with the team at the Polytechnic. It was clear from both their words and their actions that they believed that learning might be more than a ritualized dance to ensure a steady supply of compliant skilled workers who 'knew their place', and who would never be likely to 'get above themselves' by demanding learning that might be beyond the needs of the menial task in hand.

In my time at the Polytechnic I completed two professional practice dissertations. I had as my first dissertation supervisor David Megginson (1979, 2005), and for a subsequent dissertation Mike Pedler. Both of these dissertations addressed the evaluation of innovative learning practice, and great insight was gained into this topic through my supervisors' judicious mix of support and challenge. They also kept me in touch with a wider world of emergent learning practice and development, beyond the gates of my Steel Works. A powerful residual memory is of their open door policy; where there was complete porosity in terms of feeling free to walk in to their offices and picking up on whatever theme or topic was uppermost for them at that time, or indeed to interject one's own issues. There was also a sensation within that office of work being enjoyable. I found that playfulness both infectious and 
inspiring of curiosity and generative thinking. Not least though, I was in receipt of generous listening and feedback, and had been provided with a model to follow. I was also encouraged to read widely into the then radical works of Friere (1985), Berne (1961, 1964), Perls (1969, 1973), Janov (1973, 1974) and Jung (1963, 72). These theoretical influences were challenging and powerful, introducing me to broader external geopolitical themes, while concurrently taking me on deeply personal interior excursions. David Megginson provided profound direction and mentoring at a time when his thinking and practice on coaching was shaping his seminal influence on coaching practice for the next thirty years, but was rarely consciously titled 'coaching' at that time, although Megginson and Boydell did author a guide to coaching in 1979.

Mike Pedler was working on notions of learner centeredness that were to eventuate as the publication of the extensively read and continuously republished 'Managers guide to self-development' (1979). My appetite for deeper exploration of individual and organizational development themes resulted in my enrolling for the $\mathrm{MSc}$ in Management Education and Organization Development, under Prof Cary Cooper (1997, 1985), now the significant voice in Wellness and Life Balance in UK at Manchester Institute of Science and Technology (UMIST). Again, though Cooper was pushing the boundary of employee centered approaches at that time, coaching as an explicit practice was rarely mentioned.

\section{Dealing with an existential crisis}

Encouraged by the radical reading list put my way by my mentors, I found myself increasingly questioning the pathway I had taken into corporate life. In response to the same questioning, I experimented with the world of personal growth more deeply, beginning at the shallow end with workshops in 'transactional analysis' (Bern 1964) before plunging fully into the world of encounter groups, of Gestalt therapy, of Janov's 'primal screaming' therapy (1974), of counseling approaches where Roger's (1961, 1969) principle of 'unconditional positive regard' was paramount. These excursions were at once palliative, helping me cope with the tensions that were playing out in my world, both at work and privately; while at another level these growth activities were proving highly disruptive, as they opened up inner seams of my 'onion skin' that challenged my sense of my identity in the world to the core. I was excited and I was also terrified. I was quite unsure of where this was headed. Was there a place for me between a conventional career with all of the associated middle-class trappings; and the 'drop-out' alternative world 
of radical growth advocates? Looking back, there is little doubt that I was experiencing an existential crisis at that time; nor is there any doubt that that my academically based but learner-centered mentors at Sheffield and UMIST universities colleagues helped me to navigate my way through towards a middle ground between these worlds. They provided a safe container, while at the same modeling a way of successfully bringing about change from an academic positioning without getting consumed in the process.

At UMIST I encountered an American researcher, Dick Ottoway (1979), who enrolled me within his research into the characteristics of change agents and consultants. I found this research fascinating, not only for the revelations into what it takes to be an external change agent, but also because his findings chimed with my long-term goal to become an independent consultant. The intensity of this aspiration was reinforced by the day, as each successive parting of the ways from a range of jobs in engineering companies underlined my unemployability in this or probably any other conventional sector. However, by the late 1970s my career had, by a zigzag route, resulted in my receiving a job offer from Sheppard-Moscow, then a leading OD and employee development consultancy based in London. The experience gained there was to mean that, three years later, I was able to strike out on my own as an independent.

\section{Taking the coaching turn}

It was in the late seventies that my practice took an explicit 'coaching turn'. The first evidence of this was in the installing of a performance management programme for Rockwell International in the UK. This involved me in not only the design of the system but also the acculturalization of over one hundred managers and supervisors through face-to-face appraisal and development skills workshops. More often than not I was require to role-play all sorts of 'difficult' appraisals, an improvised skill at which I was to prove adept, not least with such incessant opportunity for practice.

This experience was swiftly followed by an engagement with an oil industry client for an adventitious piece of work that was to grow into a periodic engagement extending over 22 years - in some shape or form - with various parts of that client system. Interestingly the original engagement was for a series of workshops originally entitled 'Coaching and Counseling' based on work of Coverdale (1977), whose template was used to codify behaviors. These behaviors included listening, questioning, summarizing, planning - 
none too different from those that we might find in a contemporary foundation level coaching class. (I note from Coverdale's Wikipedia entry that he is styled as 'as the man who "invented" coaching and was a pathfinder in the field of inductive and experiential learning.' Quite a claim.)

The purpose of these workshops was to enable a new appraisal system, and more broadly to bring about a shift towards a more participative company culture. The workshops were well received by some, while provoking resistance in others, who re-titled the workshops 'couching and cancelling,' reflecting a British cynicism and antagonism towards therapy. Interestingly, in the eighties these workshops were rebranded as 'performance and development planning workshops,' where the 'coaching' word was removed, though the practice clearly valorized the notion of line manager as coach / mentor. At the same time the Coverdale behavioral model was dropped in favor of the Harrison Personal Power and Influence framework (1995), where the accent was placed on personal power and agency, accentuating assertive 'push' behaviors in addition to softer 'pull' skills. These skills-based interventions faced increasing demand from this corporation throughout the eighties, gaining a European foothold as the single market began to affect the whole enterprise. Meanwhile my parallel OD consulting practice was growing apace. This included a strong coaching element in support of executives navigating their enterprises through change, though this coaching activity was largely underplayed by the corporation's purse holders. It was invariably contextualized as being in service of corporate strategic change; and never articulated as being in place for personal development alone.

It was not until the early nineties that my consulting and coaching practices fused in a strategically coherent fashion. As part of a global turnaround project, a (different) oil company contracted a team of external consultants to provide one-on-one 'coaching support' to key oil-field managers across the globe - whether the managers wished to be coached or not! Interestingly, one of the oil-fields chose not to participate, while another did. The field that did embrace coaching and OD demonstrated a dramatic upturn in its financial fortunes, while the other showed little improvement. This cost-based evidence made the case for coaching more compelling than any amount of sales rhetoric, and it did much to enable my practice to grow in the nineties and beyond across the world stage. However, it was not until my return to the UK at the turn of the twenty-first century that I began to understand that coaching as an individual field and profession was being 
given credence, and that the road towards professionalization had been advanced.

\section{Making sense of the early development of my coaching practice}

Kierkegaard (1941) suggests that 'we must live our lives forwards, while understanding it backwards.' Weick (1989) in the field of management talks of 'retrospective sense making.' From the process of writing into the above narrative, following the direction of 'writing as inquiry' advocated by Richardson (2005) as a means of sense-making, then a strong basis for my coaching approach lay with my natural affinity for learner-centered approaches. 'Start where the client is at', simple though it may sound, is a presiding OD dictum that has stayed with me through my coaching career. The underlying philosophy or discourse shaping my practice was more emancipatory than managerialist (Garvey 2011) though there is evidence of a degree of a compromise with necessary managerialism to afford me a living. There is strong evidence of me seeking models of practice, especially among innovators in the field, together with evidence of a wish to share the excitement and buzz of innovative and disruptive practice. 'It begins with metaphor but ends in geometry' is an aphorism I heard in conversation with appreciative inquirer Frank Barrett. If that wisdom holds true, then I would say that I have elected for the innovative as opposed to the systematization end of the spectrum for establishing new practices.

\section{The development of my personal values, and those of my contemporaries.}

The call for papers on 'A Coach Approach' suggested that insight could be gained from an exploration of personal values underpinning the

development of a coaching practice. This reminded me that in 2006, as part of my PhD into consulting and coaching practice (Doherty 2008), I asked twenty-four independent coaches, consultants and educators about the underlying, enduring values that supported and illumined their respective practices over the past thirty years. These responses I shaped in the form of a 'collective narrative', an excerpt from which I share below. This is a synthesis account which, while written in the first-person-singular form, is based on common responses from those interviewed. I trust the sharing of this assists the reader in understanding some of the deeper motivations shaping a coach approach, not only my own but also that of my contemporaries who followed a somewhat similar path. 


\section{A narrative of independent coaches' values}

We each of us as consultants and coaches have, after thirty years of practice, ended up in a somewhat similar place, in relation to how we are positioned in the world, and in the freedoms that we have created for ourselves around the choices we make. This evident similarity is most apparent in the values that we hold. These values include openness to change, self-direction, a pursuit of excitement, a strong appetite for personal freedom and a variety of beliefs that could be broadly gathered under the banner of spirituality, though many of us take some exception to that word.

A common denominator is that in the case of each of our various professional projects or passions, the orientation towards them has been one of 'co-creation.' This activity is characterized by us working with our customers, staff, stakeholders, rather than 'doing unto them,' and not imposing upon them ideas and beliefs from the positioning of expert or guru. This co-creative preference is nowhere better illustrated than in the names of our businesses, where the co-creative propensity manifests itself as a putative brand. These names would include Co-Development International, Meta-bridge, The Space Between, and many others. These names also speak strongly to the notion of liminality, of betwixt and between, a shadowy area that is the place where much of our cocreation work is realized.

A further defining characteristic is our passion for the development process, for starting something up and taking it somewhere else while we journey together with those who are intimately involved with the project. Or through bringing into the center those who have previously been on the fringes. A belief that guides this co-creative practice is that 'change occurs in the crucible of relationship.' A corollary of this appetite for creation is that we may well be poor completers or finishers, though some would suggest that we get better at seeing things through as we grow older. We love nothing better than being in at the start up and early development of an idea of project, along with others. It enlivens and rejuvenates us.

Many of us feel that we have occupied this space called independence for most all of our lives. As we have grown up and moved through life's phases, we have naturally felt ourselves to be at some level outside of things. That is not to say that we have always been alone, far from it, but it suggests that, wherever we have landed in life, we have not felt as though we fully belonged.

This sensation of being an outsider has been there from the very beginning of our conscious lives, sometimes as a result of our positioning and roles in the family, or from profound dislocation as a result of many early geographical and education moves. We had to learn to adapt, to survive from pretty early on. These early experiences 
proved crucial in forming the independently inclined consultant that eventually burst out of the chrysalis and appeared confidently on the world stage at a much later date. For many of us, our position in family and our family circumstances meant that we felt that we were growing up as a virtual small group facilitator from quite early on in our lives.

However, it is clear from the nature of the values themselves that there is little likelihood of stabilization. This values journey is not a defined progression with a fixed end point, but a continuous process of seeking a positioning where professional practice and our personal lives are consonant with our values. These values are a work in progress, subject as they are to refining and development. This process could be compared to painting with a moving brush. There is constant oscillation. The compass point swings perpetually, though in a narrower arc as time progresses. We can be seduced far away from these values priorities by exciting looking projects that call us strongly, but experience says that these ventures rarely persist. In the end we are pulled back again towards our preferred priorities, often chastened, hurt and confused by the experience of inhabiting different social worlds that manifest radically different values systems. Our development of social identity is a continuous process of becoming, and while our sometimes chameleon nature can be confusing and frustrating for others, it has proved invaluable to us in this life of perpetual adaptation.

\section{How does the development of a coach approach differ today?}

While recently leading a Masters programme on Management Learning, I was struck by the enthusiasm of contemporary students for the work of British innovators in the field of management learning, including Pedler, Boydell, Megginson, Cooper et al. whom I had known 'before they were famous.' I was curious as to why this interest might be, given that in the passing of thirty years or more the theory and practice of management learning, of action learning, of coaching, are now codified and enshrined in textbooks, whereas in the 1970s they were little more than scribbles on flip charts and polemical writings in journals. One might think that the field had moved on, yet the voices of my formative years still speak loudly to the current generation of development professionals. What hasn't changed is that current students still face many of the same dilemmas that assailed me and my contemporaries when at a similar career stage, and in a similar profession, but in a different context. These enduring dilemmas relate to issues such as 'Do I play it safe, stay within job expectations and keep my company happy? Or do I stick my neck out, take some risk, and be transgressive?' Either way, it would seem that the power of the metaphors coined by these original thinkers remains strong, despite all attempts to reduce emancipatory 
metaphor to geometry, and to competency grids. The feedback left me feeling blessed to have been among these minds, and in some small way to have chosen to have become a pioneer among pioneers, just as number of associated waves were breaking in the world of management learning and development.

These conversations with mid-career students caused me to ask how different might it be now for a practitioner seeking to shape a coach approach for themselves, compared to how it was for me thirty years ago? Firstly the principal difference that shines through is that currently coaching is regarded by many as a profession, replete with all of the signifiers that professionalization attracts, such as the creation of professional bodies; competency girds; standards; ethics; career paths; supervisory regimes; the existence of service providers to support initiates through the various phases of professional development, together with the flourishing of academic departments and journals that support and legitimate the social construction of coaching practice. The world that aspirants now inhabit offers a significant choice of development pathways to follow, though the relative differentiators of each of these pathways is not always clear. They have many role-models, even gurus, to follow, some more substantial than others. They will have inducement to go to market through holding a coaching credential, without ever knowing the size of demand for coaching that they might meet when they venture into the world with their shiny credential. In some ways they might feel they have been sold coaching as a transactional rather than a relational type of business.

What might they hold dear that would chime with my original experience? They may well have emancipatory zeal, a wish to make the world a better place through coaching. They may have a natural empathy that would speak of an excellent fit between their virtues and this practice. They may have got lucky with an inspiring role model or two, and wish to follow their lead. They may wish to disrupt current norms and practices; or they may choose to ride the wave, to go with the flow.

What might be different is that they would have many choices of organizational positioning that were not open in my day. They might want to become an external coach, mixing that with some OD consulting as I have done, or they might want to become an 'internal coach,' pursuing their career from an in-company positioning. They may wish to integrate coaching within their approach to line management. I would hope that whatever route they choose, that they would experience a sense of discovery and excitement, 
though I fear that the commoditization process that comes hand in hand with professionalization may dull that sense of frisson. One thing for sure is that whereas in my day the market was there to be both discovered and created, right now the market is crowded. In the face of that, having the capacity to stand out from the crowd becomes ever more difficult. The answer to that challenge might be to attach oneself to the latest breaking wave, in a world where novelty is rewarded; or alternatively it might be to develop mastery in the enduring core skills and orientations that in my view have little changed over the passage of time. I trust that the reading of this piece detailing my coaching 'origin narrative' may prove helpful to those more recently in the field. This reading may encourage those practitioners to reflect upon and delineate the genesis of their particular practice; then to capitalize upon that 'origin narrative' by way of highlighting the distinctiveness of their approach to clients and fellow practitioners.

\section{References}

Berne E. (1961). Transactional analysis in psychotherapy. New York: Grove Press.

Berne E. (1964). Games people play. Harmondsworth: Penguin.

Boydell T. \& Leary M. (1996). Identifying training needs. London: IPD.

Boydell T., Leary M., Megginson D. \& Pedler M. (1991). Developing the developers. London: AMED / Department of Employment.

Cooper C.J. \& Cooper C.L. (1985). The Irrelevance of American organizational sciences to the UK and Europe. Journal of General Management, 11(2), 27-34.

Coverdale, R. (1977). Risk thinking. Coverdale organisation. Retrieved from http:/coverdalechangemanagement.com/coverdale-training/

Doherty D. (2008). On becoming an academic. (Unpublished Dissertation, University of Bristol UK). Retrieved from http://ethos.bl.uk/OrderDetails.do?uin=uk.bl.ethos. 495900

Freire P. (1970). Pedagogy of the oppressed. Harmondsworth: Penguin.

Garvey R. (2011). A very short fairly interesting and cheap book about coaching and mentoring. London: Sage. http://dx.doi.org/10.4135/9781446288443

Harrison R. (1995). The collected works of Roger Harrison. Maidenhead: McGraw-Hill.

Janov A. (1974). The primal revolution. London: Abacus.

Jaworski J. (1996). Synchronicity: The inner path of leadership. San Francisco CA: Berrett-Koehler.

Jung C. (1972). Synchronicity: An acausal connecting principle. London: Routledge Kegan Paul. 
Keirkegaard S. (1941). Fear and trembling and the sickness unto death. Princeton NJ: Princeton University Press.

Kolb D.A. (1984). Experiential learning: Experience as a source of learning and development. New Jersey: Prentice Hall.

Megginson D. \& Boydell, T. (1979). A manager's guide to coaching. BACIE. Megginson D., \& Clutterbuck D. (2005). Making coaching work: Creating a coaching culture. London: CIPD.

Pedler M., Burgoyne J., Boydell T., \& Welshman G. (eds) (1990). Selfdevelopment in organisations. Maidenhead: Mc Graw-Hill.

Pedler M., Burgoyne J., \& Boydell T. (1991). The learning company. London: McGraw-Hill.

Perls F.S. (1969). Gestalt therapy verbatim. Moab UT: Real People Press.

Perls F.S. (1973). The Gestalt approach and eyewitness to therapy. New York: Bantam Books.

Pfeiffer W. \& Jones E. (1977). Annual bandbook for group facilitators. La Jolla, Calif.: University Associates.

Richardson L. (2005). Writing: a method of inquiry. The Sage Handbook of Qualitative Research. SF: Sage pp. 959-978.

Rogers C. (1951). Client-centered therapy: Its current practice, implications and theory. Boston: Houghton Mifflin.

Rogers C. (1969). Encounter groups. Harmondsworth: Penguin.

Weick K. (2000). Making sense of the organisation. London: Blackwell. 